\title{
Certificado de boas práticas de fabricação e controle como requisito de qualificação técnica em licitações
}

Certificate of good manufacturing practices and control as technical qualification requirement in bidding

Certificación de buenas prácticas en fabricación y control como requisito de calificación técnica en pliegos

Resumo: Trata-se de estudo da legalidade da exigência em licitações públicas, a título de qualificação técnica, de apresentação de Certificado de Boas Práticas de Fabricação e Controle - CBPFC, dos produtos sujeitos à Vigilância Sanitária, documento expedido pela Agência Nacional de Vigilância Sanitária - ANVISA, a partir da legislação brasileira que rege a matéria, contextualizando com a doutrina pátria e o entendimento do Tribunal de Contas da União - TCU. A análise do tema revela o aspecto polêmico da questão e nos permitiu firmar o entendimento pela regularidade da obrigação, pois se conclui que o bem principal a ser tutelado é o direito à saúde dos cidadãos, visto que consumir produto sem a antecedente e imprescindível inspeção sanitária e consequente certificação, pode ocasionar a exposição a grave risco à saúde dos usuários, assumindo maior importância a exigência de qualificação técnica, uma vez que a qualidade do objeto contratado pela Administração Pública está diretamente relacionada à proteção da saúde da população.

Palavras-chave: Certificado. Boas Práticas. ANVISA. Licitação. Habilitação Técnica.

Abstract: Study of the legality of the requirement in public bidding, by way of technical qualification, the presentation of the Certificate of Good Manufacturing Fabrication Practices and Control - CBPFC of the products susceptible to Sanitary Surveillance, document issued by the National Agency of Sanitary Surveillance - ANVISA, from the Brazilian legislation that rule the matter, contextualizing with the homeland doctrine and the understanding of the Court Union Account - TCU. The theme analysis shows the polemic aspect of the question e allowed us to firm the understanding for the regularity of the obligation, because it concludes that the main good to be pupil is the citizens right to health, since consuming a product without the antecedent and indispensable sanitary inspection and consequent certification, may cause the exposure to serious health risk to the consumers, assuming more importance on technical qualification requirement, once the quality of the contracted object for the Public Administration is directly related to the population health protection.

Keywords: Certificate. Good Manufacturing. ANVISA. Bidding. Technic Enabling.

Resumen: Estudio acerca de la legalidad de la exigencia en pliegos gubernamentales, a título de calificación técnica, de presentación de la "Certificación de Buenas Prácticas en

\footnotetext{
1 Coordenadora da Assessoria Jurídica/Consultivo e Contratos da Federação das Indústrias do Distrito Federal - Sistema FIBRA. Brasília - Distrito Federal. Brasil. E-mail: daniella_costa@hotmail.com
} 
Fabricación y Control (CBPFC)", expedido por la Agencia Nacional de Vigilancia Sanitaria (ANVISA), con base en la normatividad brasileña acerca del tema, y teniendo en cuenta la doctrina brasileña y la jurisprudencia de la Corte de Cuentas de Brasil (TCU). El análisis del tema comprueba el aspecto controvertido de esa cuestión y se nos permite suponer tratarse de obligación regular, una vez que se concluye ser el derecho de los ciudadanos a salud el bien más relevante, pues el consumo de productos sin la previa y necesaria inspección sanitaria y la certificación resultante puede generar la exposición a severos riesgos a la salud de los usuarios. Resulta por lo tanto aún más importante la exigencia de calificación técnica pues la calidad del objeto contratado por la Administración Pública está directamente vinculada a la protección de la salud de la población.

Palabras-Ilave: Certificación. Buenas Practicas. ANVISA. Pliego. Habilitación Técnica.

\section{Introdução}

As questões relacionadas ao estudo das licitações públicas e as exigências editalícias sempre causam discussão na doutrina e perante o Poder Judiciário e as cortes de contas. Não seria diferente no caso da exigência de apresentação de Certificados de Boas Práticas de Fabricação e Controle dos produtos sujeitos à Vigilância Sanitária, documento expedido pela Agência Nacional de Vigilância Sanitária - ANVISA², que tem sido requerido pela Administração Pública, como condição de habilitação técnica, em algumas licitações.

Dessa forma, considerou-se oportuna a abordagem do tema, no âmbito administrativo $^{3}$, em razão dos incontáveis procedimentos licitatórios realizados no país para a compra de produtos sujeitos à Certificação, que impactam de forma direta na aquisição de produtos com qualidade e segurança.

Para analisar o tema e confirmar ou refutar a legalidade da eventual exigência do documento nos certames licitatórios, examinamos a legislação brasileira que rege a matéria, contextualizando com a doutrina pátria o entendimento do Tribunal de Contas da União - TCU.

\footnotetext{
2 Criada pela Lei n. 9.782/99, a Anvisa é uma autarquia sob regime especial, ou seja, uma agência reguladora caracterizada pela independência administrativa, estabilidade de seus dirigentes durante 0 período de mandato e autonomia financeira. A Agência tem como campo de atuação não um setor específico da economia, mas todos os setores relacionados a produtos e serviços que possam afetar a saúde da população brasileira. Sua competência abrange tanto a regulação sanitária quanto a regulação econômica do mercado. Além da atribuição regulatória, também é responsável pela coordenação do Sistema Nacional de Vigilância Sanitária (SNVS), de forma integrada com outros órgãos públicos relacionados direta ou indiretamente ao setor saúde. Na estrutura da administração pública federal, a Anvisa encontra-se vinculada ao Ministério da Saúde e integra o Sistema Único de Saúde (SUS), absorvendo seus princípios e diretrizes.

${ }^{3} \mathrm{Em}$ razão da delimitação deste trabalho, deixaremos de abordar o posicionamento dos tribunais pátrios sobre a matéria.
} 


\section{Metodologia}

Trata-se de pesquisa aplicada que objetiva gerar conhecimentos para adequação prática, dirigidos à solução de problema específico. O método utilizado em busca da temática proposta foi de revisão bibliográfica de literatura acadêmico-científica pertinente aos temas conexos, visando a verificar a legalidade da exigência, em licitações públicas, a título de qualificação técnica, de apresentação de Certificado de Boas Práticas de Fabricação e Controle - CBPFC para a compra de produtos sujeitos à Vigilância Sanitária. Também se realizou pesquisa documental, que se limitou a trabalhar com a legislação brasileira, regramentos do Ministério da Saúde e ANVISA - Agência Nacional de Vigilância Sanitária e jurisprudência do TCU - Tribunal de Contas da União.

A revisão da literatura acerca do tema proposto foi realizada mediante consulta à bibliografia referenciada ao final do presente artigo, no sentido de selecionar os assuntos publicados de interesse do estudo, cuja abordagem referenciasse sobre licitações e a exigência de CBPFC para a compra de produtos sujeitos à Vigilância Sanitária. A partir da leitura dos documentos encontrados, foram eleitos os que tinham uma abordagem teórica satisfatória para atingir os objetivos deste trabalho.

Quanto à análise documental, a busca em documentos legais e jurisprudência, que são componentes utilizados no processo de criação do direito, foi fundamental para aclarar as normas que regem a matéria, almejando fornecer informações relevantes para o estudo do tema.

\section{Discussão}

\section{Panorama das licitações públicas, princípios da isonomia e legalidade e dos requisitos para habilitação técnica.}

A licitação pública brasileira é um procedimento administrativo, disciplinado pela Lei n. 8.666/934 (1), que deve ser realizada pela Administração Pública quando da necessidade de celebrar contratos de aquisição, venda, contratação de obras e serviços, dentre outros. Visa a assegurar igualdade de condições a todos os interessados em contratar com o Poder Público e estabelece critérios objetivos de seleção das propostas daqueles interessados, com o fito de eleger a oferta mais vantajosa. Em razão da gestão

\footnotetext{
4 Regulamenta o art. 37, inciso XXI, da Constituição Federal, institui normas para licitações e contratos da Administração Pública e dá outras providências.
} 
de recursos públicos, devem ser observados alguns princípios e uma série de procedimentos previstos em lei.

Na visão de Meirelles (2):

Com poucas divergências, a doutrina é acorde na acentuação desses traços essenciais e de duas tradicionais finalidades da licitação - obtenção do contrato mais vantajoso e resguardo dos direitos de possíveis contratados. É preocupação que vem desde a Idade Média, e leva os Estados Modernos a aprimorarem cada vez mais o procedimento licitatório, hoje sujeito a determinados princípios, cujo descumprimento descaracteriza o instituto e invalida seu resultado seletivo.

Os princípios auxiliam na interpretação das normas jurídicas, de forma a eliminar lacunas, oferecer harmonia e coerência para o ordenamento jurídico, indicando os caminhos que os aplicadores da lei devem seguir.

Dentre os princípios que regem as licitações, para o presente estudo, analisaremos o princípio da isonomia, em razão da discussão acerca de suposta condição de desigualdade que poderia ser criada entre os interessados em participar de determinado certame que exija o Certificado de Boas Práticas de Fabricação e Controle CBPFC, bem como o princípio da legalidade, em razão de a exigência do CBPFC não estar inserta no rol do art. 30 da Lei n. 8.666/93 (1).

O princípio da isonomia, também chamado de princípio da igualdade, visa a garantir a todos os interessados em contratar com o Poder Público que lhes seja dispensado tratamento igualitário, de modo a permitir a mesma oportunidade de participação na licitação.

A isonomia tem destaque na ordem constitucional brasileira, visto que os direitos e garantias fundamentais não teriam sentido sem o princípio constitucional da igualdade, consubstanciado no art. $5^{\circ}$, caput e $1^{5}$, da Carta Magna (3).

Nesse sentido, é vedado aos agentes públicos admitir, prever, incluir ou tolerar cláusulas e condições que estabeleçam preferências ou distinções em razão da naturalidade, da sede ou domicílio dos licitantes ou de qualquer outro fator que seja irrelevante levando em consideração o objeto do contrato.

\footnotetext{
${ }^{5}$ Art. $5^{\circ}$. Todos são iguais perante a lei, sem distinção de qualquer natureza, garantindo-se aos brasileiros e aos estrangeiros residentes no País a inviolabilidade do direito à vida, à liberdade, à igualdade, à segurança e à propriedade, nos termos seguintes:

I - homens e mulheres são iguais em direitos e obrigações, nos termos desta Constituição; Isonomia de gênero para tratar de isonomia em processo licitatório? Acho melhor retirar esse inciso e só deixar o caput.
} 
Previsto no art. $5^{\circ}, 1{ }^{6}$ e direcionado especificamente à Administração Pública no art. 37, ambos da Constituição Federal (3), o princípio da legalidade limita a Administração Pública a poder exigir nos editais de licitação somente o que está previsto na lei e nas demais espécies normativas, constituindo uma garantia para os interessados, pois proíbe que o administrador inclua como requisito para habilitação qualquer documento que não tem previsão legal e que não esteja incluído na Lei n. 8.666/93 (1).

Assim, a Constituição Federal, no art. 37 (3), que trata da Administração

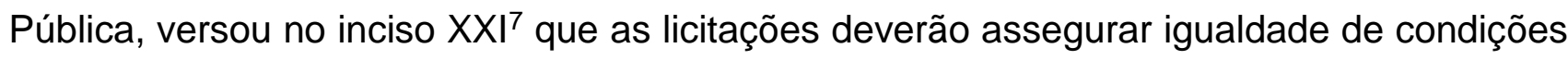
a todos os participantes e poderão estabelecer tão somente exigências de qualificação técnica indispensáveis à garantia do cumprimento das obrigações.

Inclusive, a Lei n. 8.666/93 (1) veda que os agentes públicos pratiquem atos tendentes a frustrar ou restringir o caráter competitivo da licitação, de acordo com o que se

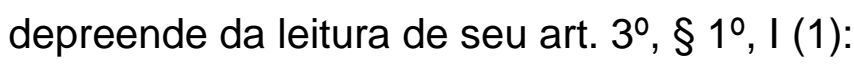

Art. 3‥ A licitação destina-se a garantir a observância do princípio constitucional da isonomia, a seleção da proposta mais vantajosa para a administração e a promoção do desenvolvimento nacional sustentável e será processada e julgada em estrita conformidade com os princípios básicos da legalidade, da impessoalidade, da moralidade, da igualdade, da publicidade, da probidade administrativa, da vinculação ao instrumento convocatório, do julgamento objetivo e dos que lhes são correlatos.

$\S 1$ ํㅡ vedado aos agentes públicos:

I - admitir, prever, incluir ou tolerar, nos atos de convocação, cláusulas ou condições que comprometam, restrinjam ou frustrem o seu caráter competitivo, inclusive nos casos de sociedades cooperativas, e estabeleçam preferências ou distinções em razão da naturalidade, da sede ou

\footnotetext{
${ }^{6}$ II - ninguém será obrigado a fazer ou deixar de fazer alguma coisa senão em virtude de lei;

7 Art. 37. A administração pública direta e indireta de qualquer dos Poderes da União, dos Estados, do Distrito Federal e dos Municípios obedecerá aos princípios de legalidade, impessoalidade, moralidade, publicidade e eficiência e, também, ao seguinte:

$(\ldots)$

XXI - ressalvados os casos especificados na legislação, as obras, serviços, compras e alienações serão contratados mediante processo de licitação pública que assegure igualdade de condições a todos os concorrentes, com cláusulas que estabeleçam obrigações de pagamento, mantidas as condições efetivas da proposta, nos termos da lei, o qual somente permitirá as exigências de qualificação técnica e econômica indispensáveis à garantia do cumprimento das obrigações.
} 
domicílio dos licitantes ou de qualquer outra circunstância impertinente ou irrelevante para o específico objeto do contrato, ressalvado o disposto nos $\S \S 50$ a 12 deste artigo e no art. 30 da Lei no 8.248, de 23 de outubro de 1991 ; $[\ldots]$

Assim, respeitando os princípios que regem as licitações públicas e considerando a natureza do objeto, o vulto da licitação ou a complexidade daquilo que se pretende contratar, a Administração define as condições para que os interessados participem do certame, estabelecendo os requisitos mínimos necessários à habilitação dos licitantes.

Todavia, tais requisitos não podem exigir a apresentação desnecessária de documentos, tampouco impor rigorismos inúteis para a habilitação dos interessados, posto que acarretará discriminação dos concorrentes em tendenciosa preferência a favorecer determinado licitante ou produto, em detrimento dos demais.

No procedimento licitatório, a Administração verifica a aptidão dos interessados à futura contratação na fase de habilitação. Aqueles que não preencham os requisitos estabelecidos no edital serão excluídos do certame em razão de ser decretada a inabilitação, que acarreta a não participação na fase de julgamento das propostas ${ }^{8}$. Para tanto, a lei de licitações, no art. $27^{9}(1)$, elenca cinco aspectos que medem a habilitação dos interessados. Discorrendo sobre a questão, Justen Filho (4) observa:

(...) elenco dos arts. 28 a 31 deve ser reputado como máximo e não mínimo. Ou seja, não há imposição legislativa a que a Administração, a cada licitação, exija comprovação integral quanto a cada um dos itens contemplados nos referidos dispositivos. O edital não poderá exigir o mais do que ali previsto. Mas poderá demandar menos.

\footnotetext{
8 Caso não tenha havido a inversão das fases de habilitação e julgamento das propostas. Do contrário, após o julgamento das propostas e antes da adjudicação, é verificada a habilitação da licitante que houver ofertado o menor preço.

9 Art.27. Para a habilitação nas licitações exigir-se-á dos interessados, exclusivamente, documentação relativa a:

I - habilitação jurídica;

II - qualificação técnica;

III - qualificação econômico-financeira;

IV - regularidade fiscal e trabalhista;

V - cumprimento do disposto no inciso XXXIII do art. $7^{\circ}$ da Constituição Federal.
} 
Quanto à qualificação técnica dos licitantes, objeto do presente estudo, a lei de licitações (1), no art. 30 permite que seja exigido apenas o rol constante nos quatro incisos, são eles:

Art. 30. A documentação relativa à qualificação técnica limitar-se-á a:

I - registro ou inscrição na entidade profissional competente;

II - comprovação de aptidão para desempenho de atividade pertinente e compatível em características, quantidades e prazos com o objeto da licitação, e indicação das instalações e do aparelhamento e do pessoal técnico adequados e disponíveis para a realização do objeto da licitação, bem como da qualificação de cada um dos membros da equipe técnica que se responsabilizará pelos trabalhos;

III - comprovação, fornecida pelo órgão licitante, de que recebeu os documentos, e, quando exigido, de que tomou conhecimento de todas as informações e das condições locais para o cumprimento das obrigações objeto da licitação;

IV - prova de atendimento de requisitos previstos em lei especial, quando for o caso.

O objetivo da norma é a ampliação do universo de licitantes e a vedação do indevido direcionamento, com o fito de estabelecer limites à discricionariedade estatal. Nesse sentido, Justen Filho (4) assevera:

Um dos caracteres mais marcantes da Lei 8.666 foi a redução da margem de liberdade da Administração Pública nesse campo e a limitação das exigências. Buscou evitar que exigências formais e desnecessárias acerca da qualificação técnica constituam-se em instrumento de indevida restrição à liberdade de participação em licitação. O objetivo é eliminar distorções ocorridas no sistema anterior, em que os requisitos de qualificação técnica acabavam por inviabilizar o acesso de muitas empresas à licitação. A legislação vigente não proíbe as exigências de qualificação técnica, mas reprime exigências desnecessárias ou meramente formais.

Oportuno destacar que Justen Filho (4) também ressalta a dificuldade do intérprete ante o referido artigo, pois é impossível que a lei desça aos pormenores de todas as exigências que a Administração deverá observar.

Como decorrência, em que pese parte da doutrina considere o art. 30 (1) como sendo de rol taxativo das exigências a título de habilitação técnica, entende-se possível que o edital fixe condições especiais para tal comprovação, de acordo com a complexidade 
do objeto do futuro contrato, invocando-se, por conseguinte, como fundamento, 0 art. 37, XXI, da CF/88 (3), que faz alusão ao termo "exigência de qualificação técnica".

Assim, verifica-se ser este o melhor posicionamento, desde que, é certo, não haja o intuito de burlar o principio da isonomia que norteia as contratações na Administração. Todavia, justificada a necessidade administrativa e o interesse público, não há como impedir que, em situações especificas, sejam estabelecidas condições particulares que denunciem a qualificação operacional dos participantes.

\section{Considerações sobre o CBPFC}

De acordo com a definição constante no revogado Decreto n. 3.961, de 10 de outubro de 2001, o Certificado de Cumprimento de Boas Práticas de Fabricação e Controle é o documento emitido pela autoridade sanitária federal declarando que o estabelecimento licenciado cumpre com os requisitos de boas práticas de fabricação e controle, tornando a empresa apta a produzir e/ou comercializar produtos sujeitos à Vigilância Sanitária.

Tal documento é indispensável ao competente registro, perante o Ministério da Saúde ${ }^{10}$, conforme a combinação dos arts. $12^{11}$ e $17^{12}$ da Lei n. 6.360/73 (5), marco legal da vigilância sanitária brasileira.

O registro sanitário é espécie de autorização prévia, sem a qual os produtos especificados na legislação não poderão ser produzidos, expostos à venda, tampouco comercializados.

De acordo com a Lei n. 9.782/9913 (6), a ANVISA é o órgão que detém competência legal para estabelecer normas, propor, acompanhar e executar as políticas, as diretrizes e as ações de vigilância sanitária; conceder registros de produtos, segundo as normas de sua área de atuação; e conceder e cancelar o certificado de cumprimento de boas práticas de fabricação.

\footnotetext{
${ }^{10}$ Atualmente, o órgão do Ministério da Saúde responsável pelo processo de registro é a ANVISA.

11 Art. 12 - Nenhum dos produtos de que trata esta Lei, inclusive os importados, poderá ser industrializado, exposto à venda ou entregue ao consumo antes de registrado no Ministério da Saúde.

12 Art. 17 - O registro dos produtos de que trata este Título será negado sempre que não atendidas as condições, as exigências e os procedimentos para tal fim previstos em lei, regulamento ou instrução do órgão competente.

13 Define o Sistema Nacional de Vigilância Sanitária, cria a Agência Nacional de Vigilância Sanitária, e dá outras providências.
} 
Conforme se depreende da lição de Pereira (7), a exigência de expedição de CBPFC decorre da referida legislação, que define o sistema de Vigilância Sanitária e criou a ANVISA. Isso porque o art. $7^{\circ}, \mathrm{XXII}(6)$, referente às competências da Agência, estatui que the cabe coordenar e executar o controle da qualidade de bens e produtos sob sua alçada, por meio de análises previstas na legislação sanitária, ou de programas especiais de monitoramento da qualidade em saúde. Ainda, compete à Agência regulamentar, controlar e fiscalizar os produtos e serviços que envolvam risco à saúde pública. Por fim, conclui por dizer que a legislação é clara em conceder à ANVISA o direito e dever de fiscalização dos produtos que ingressarão em território nacional, conhecendo as instalações físicas e as condições de sua produção.

Nesse contexto, a ANVISA é também o órgão federal responsável por realizar as inspeções, nacionais e internacionais, com o fito de fiscalizar as condições das fábricas e distribuidores e certificar, de acordo com a regulamentação técnica, que foram atendidos os requisitos necessários ao registro sanitário dos produtos no Brasil.

Por meio de Resoluções da ANVISA são estabelecidos o modo de implementação da exigência do Certificado de Boas Práticas de Fabricação e Controle para o registro de produtos sujeitos à Vigilância Sanitária e o respectivo regulamento técnico a ser seguido pelas empresas.

No exercício do poder regulamentar, a Resolução da Diretoria Colegiada da Agência - RDC n. 16 (8), de 28 de março de 2013, aprova o Regulamento Técnico de Boas Práticas de Fabricação de Produtos Médicos e Produtos para Diagnóstico de Uso In Vitro. Nele são estabelecidos os requisitos aplicáveis à fabricação desses produtos, de forma a descrever as Boas Práticas de Fabricação (BPF) para métodos e controles usados no projeto, compras, fabricação, embalagem, rotulagem, armazenamento, distribuição, instalação e assistência técnica dos produtos médicos e produtos para diagnóstico de uso in vitro.

Na mesma esteira, a RDC n. 39 (9), de 14 de agosto de 2013, institui procedimentos administrativos para a concessão das Certificações de Boas Práticas de Fabricação de Medicamentos, Produtos para Saúde, Cosméticos, Perfumes, Produtos de Higiene Pessoal, Saneantes e Insumos Farmacêuticos e das Certificações de Boas Práticas de Distribuição e/ou Armazenagem de Medicamentos, Produtos para Saúde e Insumos Farmacêuticos. 
Pereira (7) destaca que a exigência da expedição do CBPFC está clara e adequadamente normatizada, e sem contestação quanto à legalidade e/ou constitucionalidade de sua exigência.

Estamos diante, portanto, de precauções para a proteção da saúde pública, posto ter como principal objetivo assegurar que os produtos sejam seguros e eficazes, a garantir a qualidade dos produtos comercializados no Brasil, conforme explica Souza (10):

Nos termos dos citados atos regulatórios, a certificação de boas práticas de fabricação tem a finalidade de garantir a qualidade do processo de fabricação e o controle dos fatores de risco à saúde do consumidor. Assim, consiste em um importante requisito para a concessão do registro de dispositivos médicos, contribuindo para a segurança de seu uso por potenciais pacientes nos mais diversos procedimentos de saúde.

Assim, nenhum dos produtos submetidos ao regime de vigilância sanitária poderá ser industrializado, exposto à venda ou entregue ao consumo, antes de registrado no órgão de vigilância sanitária competente. Sendo necessária, para o registro, a comprovação por intermédio de inspeção sanitária de que o estabelecimento de produção cumpre as boas práticas de fabricação e controle, mediante a apresentação do certificado de Cumprimento de Boas Práticas de Fabricação e Controle (CBPFC).

Pode-se concluir, portanto, que as resoluções da ANVISA, ou mesmo outras normas editadas que direcionam a análise pormenorizada das questões técnicas que envolvem o assunto, devem ser observadas pelas empresas que produzem ou comercializam os produtos objeto do estudo.

\section{Da exigência de CBPFC nas licitações públicas}

Em 2003, a ANVISA editou a Cartilha "Vigilância Sanitária e Licitação Pública" (11), documento que objetiva, ao disseminar subsídios técnicos para os certames licitatórios, oferecer apoio aos responsáveis do setor público para que identifiquem com maior tranquilidade a situação dos candidatos a fornecedores quanto à regularidade junto aos órgãos que se ocupam da avaliação do risco e da qualidade.

Nos termos da cartilha, os órgãos licitantes são corresponsáveis por garantir a segurança sanitária de produtos e serviços, na medida em que efetivamente procedem às contratações, que devem primar pela situação regular e de qualidade, pois são os primeiros da cadeia de distribuição a ter contato com o que será utilizado nos serviços públicos. 
Nesse sentido, devem propiciar condições ótimas para que os procedimentos adotados pelos profissionais de saúde produzam o efeito desejado. Isso porque, nesse campo, deve-se evitar, a todo custo, exposição desnecessária a riscos.

Assim, a Cartilha sugere que o proponente deve dispor de condições para executar satisfatoriamente o objeto da licitação, as quais serão aferidas mediante os requisitos de habilitação. $\mathrm{E}$, dentre esses, para a qualificação técnica, indica que deverão constar em edital, obrigatoriamente, os requisitos exigidos pela Vigilância Sanitária para garantir que os proponentes, interessados em fornecer seus produtos e serviços aos entes públicos, sejam empresas idôneas, inspecionadas periodicamente e assegurem que a qualidade de seus produtos atenda aos requisitos técnicos necessários. Dessa forma, orienta que caberá à empresa proponente apresentar, dentre outros, o CBPFC.

Impende ressaltar, neste momento, que exigência editalícia de apresentação de CBPFC é revestida de polêmica, porquanto, de um lado, há o entendimento de que, por não estar inserto no rol do art. 30 da Lei 8.666/93 (1), a obrigação do Certificado afrontaria o princípio da legalidade. De igual sorte, também se questiona se afrontaria a isonomia entre os participantes, caso ficasse comprovada o estabelecimento de condição de desigualdade entre os interessados em contratar com a Administração. Ainda, segundo Souza (10), gera conflitos entre o interesse público na proteção à saúde e o interesse privado de exercer a atividade econômica regulamentada.

Ocorre que tais compreensões são limitadas.

Não há adequada interpretação do inciso IV do art. 30 (1), ao desconsiderar que o gestor público pode - e deve - requerer documentos previstos em lei especial, com o intuito de aferir se o interessado está apto tecnicamente à contratação.

Nesse sentido, ante a necessidade de resguardar o interesse público afeto, caso a legislação pertinente exija determinada documentação, é dever da Administração solicitar a título de qualificação técnica.

Ainda, não há que se falar em restrição ao caráter competitivo da licitação, posto que somente haveria afronta à isonomia no caso de exigência ilegal, excessiva ou desarrazoada, o que não é o caso.

A comprovação do CBPFC é uma exigência normatizada pela ANVISA que é, por lei, responsável pela regulação e controle do sistema de vigilância sanitária (6), está amparada na extensa legislação amplamente referenciada ao longo do texto. Ainda, a 
edição de Resolução da Diretoria Colegiada não transbordaria os limites legais, estando em consonância com o art. 7º, inciso X, da Lei 9.782/99 (6).

\section{Posicionamento do TCU}

Atualmente, o Tribunal de Contas da União (TCU), em análise sobre a questão jurídica da legalidade de exigência do CBPFC como requisito para habilitação dos licitantes, ainda não firmou um posicionamento cristalizado sobre o tema ${ }^{14}$. São esses os pontos que merecem destaques a seguir.

Manifestando-se sobre a matéria, o TCU vinha entendendo, em diversos julgados $^{15}$, que a exigência de certificado de boas práticas de fabricação não se coaduna com os requisitos de habilitação previstos na Lei n. 8.666/93 (1) e que o art. 30 da lei de licitações enumera os documentos que poderão ser exigidos para fim de comprovação da qualificação técnica, entre os quais não se incluem certificados de qualidade. Nesse contexto, vinha determinando o TCU que a Administração Pública exclua dos editais a exigência do CBPFC, por absoluta falta de amparo legal, bem como por não se mostrar indispensável à garantia do cumprimento das obrigações a serem pactuadas. Nesse sentido tem-se o Acórdão n. 0392-05/11-P (12):

Não se deve perder de perspectiva que as exigências de qualificação técnica têm por escopo aferir a aptidão da licitante para desempenho de atividade compatível com o objeto da licitação, à luz do inc. II do aludido art. 30. E tal

\footnotetext{
${ }^{14}$ A exigência de apresentação do CBPFC, em licitações, das empresas que fabricam ou comercializam medicamentos, não costuma ser entendida como ilegal pelo TCU, em razão do Tribunal a considerar prevista no Sistema Nacional de Vigilância Sanitária, em especial, na Lei n. 6.360/76 e na Lei n. 9.782/99, e nos Decretos n. 79.094/77 e no Decreto n. 8.077/13, destacando-se que este último, ao regulamentar as condições de funcionamento das empresas sujeitas à fiscalização da vigilância sanitária, entende, no art. 15, que a ação de vigilância sanitária implicará a fiscalização de todos os produtos de que trata o Decreto, inclusive os isentos de registro, os estabelecimentos de fabricação, distribuição, armazenamento e venda e os veículos destinados ao transporte dos produtos, para garantir o cumprimento das boas práticas e das exigências da legislação vigente. Ademais, também entende que o CBPFC também está previsto na Portaria Interministerial MP/MS/MCT/MDIC n. 128/08, que estabelece diretrizes para a contratação pública de medicamentos e fármacos pelo Sistema Único de Saúde - SUS, quando aduz, no art. $2^{\circ}$, $\S 1^{\circ}$, que a fim de garantir o pleno atendimento de todas as exigências sanitárias nacionais nas aquisições de medicamentos acabados por entidades da Administração Pública Direta ou Indireta, serão preferenciais as licitações de âmbito nacional e que nas aquisições de medicamentos acabados, deverá estar prevista no instrumento convocatório a exigência de apresentação do certificado de registro do produto e do certificado de boas práticas de fabricação do produtor, emitidos pela ANVISA, bem como declaração do produtor, sujeita à comprovação, referente à origem do produto acabado e do insumo farmacêutico ativo que o compõe.

15 Colacionamos, como exemplo, os processos TC n. 033.876/2010-0, TC n. 028.481/2009-8 e TC n. 028.482/2009-5.
} 
aptidão deve ser comprovada mediante atestados fornecidos por pessoas jurídicas devidamente registradas (§ $\left.1^{\circ}\right)$, nos quais conste declaração de que executou objeto similar ao licitado, e não mediante certificações de qualidade.

É preciso considerar também que, no âmbito federal, não foi editada lei especial que obrigue a apresentação dos certificados em questão para fim de habilitação em certames licitatórios, o que afasta a possibilidade de enquadramento dessa exigência no inc. IV do mencionado art. 30 .

Apenas a título de argumentação, ainda que se considerasse legal a exigência supra, ela não atenderia, no caso concreto, ao princípio da proporcionalidade, não se revelando, na espécie, indispensável à garantia do cumprimento das obrigações a serem assumidas perante o Ministério da Saúde.

Aliás, como bem evidencia a representante (peça 1, pp. 67 ), já estariam sendo formuladas às licitantes exigências tanto quanto à sua constituição e operação, quanto ao registro e comercialização de produtos - que juntas asseguram a regularidade sanitária da empresa e dos produtos por ela fabricados ou importados. Seria, assim, desnecessária, desarrazoada, desproporcional a exigência de qualquer tipo de certificado com esse mesmo desiderato. [...]

Todavia, diante de inúmeros processos de representação, questionando a exigência objeto deste estudo, o TCU decidiu, em 2014, que embora razoável, a exigência do CBPF refoge à exaustiva documentação prevista no art. 30 da Lei 8.666/1993, necessitando que o assunto seja melhor estudado, de forma uniforme e sistêmica, por parte da secretaria especializada da Corte de Contas (13). E complementa aduzindo a necessidade de que seja dispensado tratamento sistêmico e igualitário ao exame da legalidade da exigência, previsto na Portaria MS n. 2814/98, com o fito de resguardar o interesse público presente nas aquisições de medicamentos, com a observância dos devidos cuidados sanitários na sua fabricação, bem como a segurança jurídica e a presunção da legalidade e legitimidade dos atos dos gestores públicos praticados em observância às orientações normativas do Ministério da Saúde e da ANVISA.

Tanto que a SECEX/SAÚDE, unidade técnica do TCU que tem por competência assessorar os relatores em matéria inerente ao controle externo da área da saúde e 
oferecer subsídio técnico para o julgamento das contas e apreciação dos demais processos relativos às unidade jurisdicionadas ao TCU, bem como realizar trabalhos de fiscalização, instaurou o processo de representação, autuado sob o número 1.103/2015-6, em cumprimento ao Acórdão n. 1392/2014 (13) para dar tratamento sistêmico e uniforme ao exame da legalidade da exigência, para fins de habilitação em licitações públicas, do CBPFC, previsto na Portaria MS n. 2.814/98. O referido processo é de caráter restrito e ainda não teve pronunciamento conclusivo.

Em que pese o estágio da Representação, a jurisprudência mais recente do TCU não mais se fixou em considerar ilegal a exigência do CBPFC, mesmo reconhecendo que o procedimento pudesse violar a exaustividade do rol de exigências para qualificação técnica, insculpido no art. 30 da Lei n. 8.666/93 (1).

Nesse sentido, o Acórdão n. 7783/2015 (14) conclui que não seria oportuno admitir-se que a exigência do CBPFC não encontra amparo legal, pois atropelaria o estudo técnico aprofundado que se realiza pela unidade técnica especializada (SecexSaúde). Além disso, decide no sentido de que considerar ilegal a exigência conduziria à anulação de certames realizados e à necessidade de promoção de novos procedimentos licitatórios, num futuro incerto, o que decerto traria prejuízos sociais decorrentes dos atrasos no fornecimento dos produtos aos beneficiários necessitados. Aliado a isso, entende que é dever reconhecer que a exigência do requisito de apresentação do CBPFC não é, em primeira análise, desarrazoada, sendo usual nos certames para aquisição de medicamentos, além de encontrar amparo na legislação específica e respaldo judicial. Trata-se, portanto, de matéria complexa e que, de fato, merece um estudo aprofundado, como aquele que se desenrola na SecexSaúde.

Inclusive, cumpre ressaltar que o TCU, no relatório de Auditoria Operacional nas Ações de Vigilância Sanitária de Medicamentos (TC-017.238/2006-3), menciona a importância do CBPFC para o registro de produtos sujeitos à Vigilância Sanitária e para a participação em licitações públicas.

\section{Considerações finais}

Não se pode perder de vista que o bem principal a ser tutelado é o direito à saúde dos cidadãos, e não a satisfação dos lucros das empresas produtoras de bens nessa área, conforme Pereira (7). 
É dever do Estado zelar pela saúde pública, conforme expresso na Constituição Federal. Como direito social, reveste-se de relevância pública as ações e serviços de saúde, cabendo ao Poder Público dispor, nos termos da lei, sobre sua regulamentação, fiscalização e controle.

A importância do tema reside no fato de que, ao consumir produto sem a antecedente e imprescindível inspeção sanitária e consequente certificação, podemos estar diante de grave risco à saúde dos usuários, assumindo maior consideração a exigência de qualificação técnica, uma vez que a qualidade do objeto contratado pela Administração Pública está diretamente relacionada à proteção da saúde da população.

Não é possível permitir que a população fique exposta a produtos sem o competente controle sanitário, devendo ser reconhecida a importância social da certificação.

Por todo o exposto, está claro que não há rigorismo formal em requerer a apresentação de documento que a legislação sanitária entende como imprescindível, posto que os riscos na utilização de produtos sujeitos à Vigilância Sanitária devem ser reduzidos.

A exigência de apresentação de CBPFC pelos licitantes encontra respaldo na legalidade, constituindo-se também em parte integrante e fundamental da precaução no trato com as questões que envolvem a saúde dos usuários, na medida em que a aquisição de produtos não seguros pode gerar dano irreparável à saúde pública e ocasionar dano ao erário, na hipótese de eventual aquisição em regime de urgência, ante a suspensão ou frustração de certame licitatório.

Deve-se entender o CBPFC como um dos atributos de qualidade que assegura que os produtos são consistentemente produzidos e controlados, com padrões de qualidade apropriados para 0 uso pretendido e requerido pelo registro, sendo imprescindível para se verificar a procedência dos produtos a serem consumidos, ainda mais se considerarmos as denúncias de práticas ilegais de produção e comercialização que assolam a população, enfraquece o sistema sanitário e, por conseguinte, urge que a Administração Pública utilize meios de impedir tais práticas. 


\section{Referências}

1 Brasil. Lei n. 8.666, de 21 de junho de 1993. Regulamenta o art. 37, inciso XXI, da Constituição Federal, institui normas para licitações e contratos da Administração Pública e dá outras providências. [Internet]. Brasília, 22 de junho de 1993 [Acesso em 3 out 2015]. Disponível em: http://www.planalto.gov.br/ccivil_03/Leis/L8666compilado.htm

2 Meirelles HL. Direito Administrativo Brasileiro. São Paulo: Malheiros, 2013.

3 Brasil. Constituição da República Federativa do Brasil, de 8 de outubro de 1988. [Internet] Brasília: 9 de outubro de 1988. [Acesso em 3 out 2015]. Disponível em: http://www.planalto.gov.br/ccivil_03/constituicao/ConstituicaoCompilado.htm

4 Justen Filho M. Comentários à lei de licitações e contratos administrativos. São Paulo: Revista dos Tribunais, 2014.

5 Brasil. Lei n. 6.360, de 23 de setembro de 1976. Dispõe sobre a Vigilância Sanitária a que ficam sujeitos os Medicamentos, as Drogas, os Insumos Farmacêuticos e Correlatos, Cosméticos, Saneantes e Outros Produtos, e dá outras Providências. [Internet]. Brasília, 24 de setembro de 1976 [Acesso em 3 out 2015]. Disponível em:

http://www.planalto.gov.br/ccivil_03/leis//6360.htm

6 Brasil. Lei n. 9.782, de 26 de janeiro de 1999. Define o Sistema Nacional de Vigilância Sanitária, cria a Agência Nacional de Vigilância Sanitária, e dá outras providências. [Internet]. Brasília, 27 de janeiro de 1999 [Acesso em 3 out 2015]. Disponível em: http://www.planalto.gov.br/ccivil_03/leis/L9782.htm

7 Pereira PP. Certificado de boas práticas de fabricação e controle: visão do poder judiciário perante a mora da ANVISA. In: Delduque, MC; Alves, SMC; Dino Neto. N, organizadores. Direito Sanitário em Perspectiva - Volume 4. Brasília: ESMPU e Fiocruz, 2015, p.647-668.

8 Brasil. ANVISA. Resolução da Diretoria Colegiada da Agência - RDC n. 16 de 28 de março de 2013. Aprova o Regulamento Técnico de Boas Práticas de Fabricação de Produtos Médicos e Produtos para Diagnóstico de Uso In Vitro. [Internet]. [Acesso em 3 out 2015]. Disponível em: http://bvsms.saude.gov.br/bvs/saudelegis/anvisa/2013/rdc0016_28_03_2013.pdf

9 Brasil. ANVISA. Resolução da Diretoria Colegiada da Agência - RDC n. 39 de 14 de agosto de 2013. Dispõe sobre os procedimentos administrativos para concessão da Certificação de Boas Práticas de Fabricação e da Certificação de Boas Práticas de Distribuição e/ou Armazenagem. [Internet]. [Acesso em 3 out 2015]. Disponível em: http://bvsms.saude.gov.br/bvs/saudelegis/anvisa/2013/rdc0039_14_08_2013.html

10 Souza MDC. A judicialização da mora administrativa da ANVISA na concessão do certificado de cumprimento de boas práticas de fabricação e controle junto ao Tribunal 
Regional Federal da primeira região - seção judiciária do Distrito Federal. In: Delduque, MC; Alves, SMC; Dino Neto. N, organizadores. Direito Sanitário em Perspectiva - Volume 4. Brasília: ESMPU e Fiocruz, 2015, p.628 646.

11 Brasil. ANVISA. Vigilância Sanitária e Licitação Pública [Internet]. Brasília, 2003. [Acesso em 3 out 2015]. Disponível em:

http://www.anvisa.gov.br/divulga/cartilha_licitacao.pdf

12 Brasil. Tribunal de Contas da União. Tomada de Contas n. 033.876/2010-0 - Acórdão n. 0392-05/2011-P - Plenário, Relator: Ministro José Jorge. Brasília, 16 fev 2011.

13 Brasil. Tribunal de Contas da União. Tomada de Contas n. 005.542/2014-6 - Acórdão n. 1392-19/2014-P - Plenário, Relator: Ministra Ana Arraes. Brasília, 28 mai 2014.

14 Brasil. Tribunal de Contas da União. Tomada de Contas n. 028.396/2014-6 - Acórdão n. 7783/2015 - Segunda Câmara, Relator: Ministro-Substituto André Luís de Carvalho. Brasília, 22 set 2015. 